\title{
The value of immunotherapy in pediatric leukemia and lymphoma
}

\author{
Elisabeth Salzer (D) A Andishe Attarbaschi
}

Received: 22 July 2021 / Accepted: 27 September 2021 / Published online: 8 November 2021

(C) The Author(s) 2021

\begin{abstract}
Summary Leukemia and lymphoma are a leading cause of cancer-related mortality in children and the prognosis for patients with relapsed or refractory disease remains poor. Standard therapies are associated with a wide array of acute and long-term toxicities. Immunotherapy is changing the treatment landscape for pediatric leukemia and lymphoma patients and has advanced at a tremendous pace over the last decade. Immunotherapies are thought to exhibit fewer long-term toxicities than chemotherapy and radiation, which makes it very appealing in the field of pediatrics. These novel therapeutic concepts may overcome resistance to and decrease side effects of standard therapy. Many therapies are currently being investigated, from immunomodulatory agents to adoptive cell therapy, bispecific T-cell engagers, oncolytic virotherapy, and checkpoint inhibition. A critical challenge that must be overcome is the identification of biomarker(s) to identify patients who would benefit from immunotherapy.
\end{abstract}

Keywords Pediatric leukemia and lymphoma • Immunotherapy $\cdot$ Innovative treatments

\section{Introduction}

The treatment of pediatric leukemia and lymphoma, impacting more than $30 \%$ of childhood cancer patients, has undergone substantial progress over the last decade [1-4]. Despite this, leukemia remains

\footnotetext{
E. Salzer $(\bowtie) \cdot$ A. Attarbaschi

St. Anna Children's Hospital, Pediatric Hematology and Oncology, Department of Pediatrics and Adolescent Medicine, Medical University of Vienna, Vienna, Austria elisabeth.salzer@stanna.at
}

A. Attarbaschi

andishe.attarbaschi@stanna.at a leading cause of pediatric cancer-related mortality and the prognosis for individuals with relapsed or refractory disease remains poor. Standard therapies are associated with a wide array of acute and longterm toxicities and further treatment intensification may not be tolerable or beneficial, necessitating novel targeted approaches. While most immunotherapyrelated studies have focused on adult malignancies, a handful of these therapies have also recently found success in the field of pediatrics. Immunotherapy is changing the treatment landscape for pediatric leukemia and lymphoma patients and has advanced at a tremendous pace over the last decade.

However, the concept of immunotherapy for cancer is not new and has been documented since the 19th century [5-7]. The immune system is a highly complex organization of cells and proteins that cooperate to eliminate infections while maintaining tolerance against self. The complex interplay between the patient's immune system and cancer is also termed 'immunoediting' and includes immune surveillance, immune cell infiltration, and tumor cytolysis [8-11]. Immunoediting itself can further be divided in three different phases: elimination, equilibrium, and escape [12]. Immunotherapies aim to counteract the escape phase and reinvigorate the patient's immune system to recognize and eliminate cancer cells. These approaches may overcome resistance to and decrease side effects of standard therapy. Many therapies are currently being investigated, from immunomodulatory agents to adoptive cell therapy, bispecific T-cell engagers, oncolytic virotherapy, and checkpoint inhibition. In pediatric leukemia and lymphoma antibody therapy, antibody-drug conjugates (ADC), bi-specific T-cell engagers (BiTE), and chimeric antigen receptor (CAR) T cells have shown most promising and will be discussed in detail and are summarized in Fig. 1. 
Antibody and Antibody-like therapy
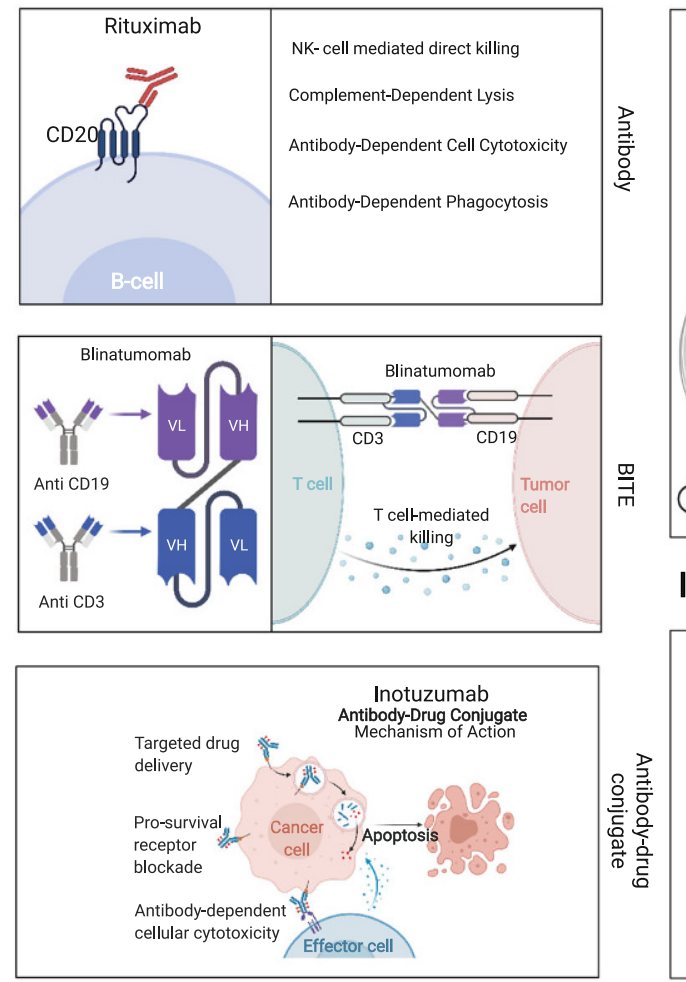

Fig. 1 Schematic representation of immunotherapy options in pediatric leukemia and lymphoma. Antibody and antibody-like therapy (left) is illustrated by the examples of rituximab, blinatumomab, and inotuzumab. For adoptive therapies

\section{Antibody and antibody-like therapy}

Antibody therapy has been used in many pediatric cancer types and has shown much promise. Monoclonal antibodies (mAbs) attach to a specific tumor surface antigen resulting in activation of NK cells and macrophages via Fc-receptor binding. Once activated, these cells release cytotoxic granules to kill the tumor cell in a process called antibody-dependent cellular cytotoxicity [13]. mAbs are tumor-specific instead of patient-specific and can be easily stored without the need for local manufacturing expertise. Rituximab, a CD20-specific mAb, was the first mAb approved for clinical use in 1997 for adults. In pediatric non-Hodgkin lymphoma (NHL) patients, the addition of rituximab to standard chemotherapy increased the 1-year event-free survival (EFS) from 81.5 to $94.2 \%$ [14]. Anti-CD22 mAbs have been successfully utilized in both adult and pediatric B-cell acute lymphoblastic leukemia (ALL) [15-17]. Brentuximab vedotin, an anti-CD30 mAb drug conjugate (ADC), was approved by the US Food and Drug Administration (FDA) in 2011 for relapsed or refractory Hodgkin lymphoma (HL) and anaplastic large-cell lymphoma. A higher overall response rate was seen in patients with relapsed/refractory HL who received brentuximab vedotin compared with vinorelbine [18]. In a phase III chimeric antigen receptor (CAR) T cell therapy is shown (top right) and checkpoint inhibitor therapy is shown with the example of PD1-checkpoint therapy (nivolumab; bottom right). The figure was generated using Biorender

Children's Oncology Group study, the combination of brentuximab vedotin with gemcitabine for relapsed HL is being evaluated (NCT01780662).

BiTEs consist of two single-chain variable fragments connected by a flexible linker. They connect and activate $\mathrm{T}$ cells with the tumor-specific antigen, where one side binds to the CD3 receptor of the T cell and the other side to the tumor antigen, resulting in the activation of $\mathrm{T}$ cells and subsequent cytolysis of the tumor cell [19]. Blinatumomab, a CD19/antiCD3 BiTE, was approved by the FDA in 2017 for the treatment of relapsed or refractory B-cell ALL in the pediatric population after being approved in 2014 for adult patients. Overall survival (OS), remission rates, and EFS were significantly longer or higher in the blinatumomab group compared with standard chemotherapy [20,21]. Blinatumomab has also been approved for the treatment of minimal residual disease positive B-cell ALL patients.

\section{Allogeneic hematopoietic stem cell transplantation (aHSCT) and adoptive cell therapy}

HSCT is the most established and commonly used cellular immunotherapy in cancer care. It is the most potent anti-leukemic therapy in patients with acute 
myeloid leukemia and is routinely used with curative intent in patients with intermediate and high/ very-high risk disease or at relapse for patients with NHL. Donor T cells, and possibly other immune cells, eliminate residual leukemia cells after prior (radio)chemotherapy. This immune-mediated response is known as graft-versus-leukemia (GvL) [22, 23]. After allo-HSCT, relapse is still a major complication and current evidence suggests that relapse is not due to clonal evolution, but instead to the ability of tumor cells to escape immune control by a variety of mechanisms such as by decreasing human leukocyte antigen (HLA) expression and/or tumor antigens.

The most successful option to overcome this challenge are chimeric antigen receptor $\mathrm{T}$ cells (CART) [24]. A chimeric antigen receptor is composed of an extracellular domain with an antigen-binding domain derived from a monoclonal antibody specific for a tumor surface antigen, a spacer domain, a transmembrane domain, and an intracellular signaltransducing chain of the T-cell receptor. CAR-Ts are able to engage a specific antigen without the need of HLA presentation of tumor neoantigens [25]. The most impressive immunotherapy results have come from the CD19 CAR-T therapy in both adult [26, 27] and pediatric patients $[28,29]$ with chemotherapy resistant B-cell ALL and the CD19 CAR-T therapy $\left(\mathrm{Kymriah}^{\circledR}\right)$ was approved by the FDA in 2017. However, more CAR-T therapy targets are needed for hematologic malignancies, as illustrated by patients who experience relapse after CD19 CAR-T therapy. Novel CAR-Ts for leukemia and lymphoma patients targeting CD-22 [30, 31], CD30 [32], CD123 [33], and thymic stromal lymphopoietin receptor [34], respectively are currently tested in preclinical and clinical model systems.

Natural killer (NK) cells recognize a target without engaging specific antigens. The concept of utilizing NK cells to destroy tumor cells stems from experiments in murine leukemia models [35] and has been verified in preclinical and clinical trials of adult AML patients [36] and later also pediatric AML patients [37]. Currently, there are only a few clinical trials utilizing NK cell therapy for pediatric hematologic malignancies, as the concept is rather pursued for pediatric solid tumors.

\section{Checkpoint inhibitors}

Immune checkpoints are key regulators to prevent auto-immune activity that when stimulated dampen the immune response to an immunologic stimulus. Studies have shown that immunogenic tumors can escape immune surveillance by reducing an oncolytic immune response via expression checkpoint ligands [38]. Two of the most commonly applied checkpoint inhibitors target PD1-PD1-L and the CTLA4-CD80/86 axis [39]. CTLA-4 is expressed on the surface of activated $\mathrm{T}$ cells and binds to CD80/86 on dendritic cells (DCs), leading to deactivation of the T cell [40]. CTLA-4 checkpoint inhibition is widely used for adult solid tumor therapy (e.g., melanoma, lung, and kidney cancers), but only limited data exist for pediatric solid tumor therapy (e.g., metastatic melanoma [41]).

PD-1 is expressed on chronically activated T cells, $\mathrm{B}$ cells, DCs, and macrophages. Under physiological circumstances, PD-1 signaling limits the inflammatory immune response to prevent autoimmunity [38]. Experience in pediatric hematological malignancies is limited to Hodgkin's disease and non-Hodgkin's lymphoma as in the ongoing Children's Oncology Group (COG) protocol ADVL1412 [42]. In March 2017, the FDA approved pembrolizumab, the anti-PD1 antibody, for the treatment of adults and children with refractory classic HL or those who relapsed after three or more prior treatments [43].

One of the hypotheses to explain the differences in response rates between certain adult cancers compared with pediatric cancers is the mutational load or lack thereof. As pediatric cancers in general do not have a high mutational burden in their tumors, decreased immunogenicity is suspected [44]. One exception involves pediatric patients with biallelic mismatch repair deficiency. These patients have a very high risk of cancer throughout life and their tumors are associated with an exceptionally high mutational burden, even higher than adult cancers. The PD-1 antibody pembrolizumab has been shown efficient for the treatment of mismatch repair deficiency tumors in patients 12 years and older [45].

\section{Limitations and challenges}

Despite the promising developments in immunotherapy for adult oncology, fewer successes have been achieved in the pediatric setting. This result may in part be due to the significantly lower mutational load in pediatric cancers, which limits the number of neoantigens for immunotherapies to target. A critical challenge that must be overcome is the identification of biomarker(s) to identify patients who would benefit from immunotherapy. Much research is being focused on which biomarkers will be predictive and prognostic for these patients. Still, immunotherapies are thought to exhibit fewer long-term toxicities than chemotherapy and radiation, which makes it very appealing in the field of pediatrics. With few downsides and the potential for disease cures, immunotherapy in the pediatric population has the potential to move to the front-line of therapeutic options [46].

Although the ultimate contribution of immunotherapies to the treatment and outcome of pediatric cancer patients remains uncertain, the landscape of therapy in the near future is likely to be quite different from traditional surgery, radiation, and chemotherapy. 


\section{Take Home Message}

The use of immunotherapy for pediatric leukemia and lymphoma patients has been successful in creating durable remissions for multiply relapsed and refractory patients who previously had little chance of cure. The ongoing clinical and preclinical work continues to advance our understanding of these immune-based therapies and will shape the next generation of clinical trials.

Funding Open access funding provided by Medical University of Vienna.

Conflict of interest E. Salzer and A. Attarbaschi declare that they have no competing interests.

Open Access This article is licensed under a Creative Commons Attribution 4.0 International License, which permits use, sharing, adaptation, distribution and reproduction in any medium or format, as long as you give appropriate credit to the original author(s) and the source, provide a link to the Creative Commons licence, and indicate if changes were made. The images or other third party material in this article are included in the article's Creative Commons licence, unless indicated otherwise in a credit line to the material. If material is not included in the article's Creative Commons licence and your intended use is not permitted by statutory regulation or exceeds the permitted use, you will need to obtain permission directly from the copyright holder. To view a copy of this licence, visit http://creativecommons.org/licenses/by/4.0/.

\section{References}

1. Leukemia \& Lymphoma Society ${ }^{\circledR}$ (LLS). Childhood and adolescent blood cancers. 2021. https://www.lls.org/ facts-and-statistics/childhood-blood-cancer-facts-andstatistics. Accessed 10 June 2021.

2. Oeffinger KC, et al. Chronic health conditions in adult survivors of childhood cancer. NEnglJ Med. 2006;355:1572-82.

3. Kaspers GJL, Creutzig U. Pediatric acute myeloid leukemia: international progress and future directions. Leukemia. 2005;19:2025-9.

4. Armstrong GT, et al. Late mortality among 5 -year survivors of childhood cancer: a summary from the childhood cancer survivor study. JClin Oncol. 2009;27:2328-38.

5. Nauts HC, Fowler GA, Bogatko FH. A review of the influence of bacterial infection and of bacterial products (Coley's toxins) on malignant tumors in man; a critical analysis of 30 inoperable cases treated by Coley's mixed toxins, in which diagnosis was confirmed by microscopic examination selected for special study. Acta Med Scand Suppl. 1953;276:1-103.

6. Coley WB II. Contribution to the knowledge of sarcoma. Ann Surg. 1891;14:199-220.

7. McCarthy EF. The toxins of William B. Coley and the treatment of bone and soft-tissue sarcomas. Iowa Orthop J. 2006;26:154-8.

8. Zitvogel L, et al. The anticancer immune response: indispensable for therapeutic success? J Clin Invest. 2008;118:1991-2001.

9. Roberts SS, Chou AJ, Cheung N-KV. Immunotherapy of childhood sarcomas. Front Oncol. 2015;5:181.

10. Burnet M. Cancer: a biological approach. III. Viruses associated withneoplastic conditions. IV. Practical applications. BrMed J. 1957;1:841-7.
11. Dunn GP, Bruce AT, Ikeda H, Old LJ, Schreiber RD. Cancer immunoediting: from immunosurveillance to tumor escape. Nat Immunol. 2002;3:991-8.

12. Schreiber RD, Old LJ, Smyth MJ. Cancer immunoediting: integrating immunity's roles in cancer suppression and promotion. Science. 2011;331:1565-70.

13. Melero I, Hervas-Stubbs S, Glennie M, Pardoll DM, Chen L. Immunostimulatory monoclonal antibodies for cancer therapy. Nat Rev Cancer. 2007;7:95-106.

14. Minard-Colin V, et al. Results of the randomized Intergroup trial Inter-B-NHL ritux 2010 for children and adolescents with high-riskB-cell non-Hodgkinlymphoma (B-NHL) and mature acute leukemia (B-AL): Evaluation of rituximab (R) efficacy in addition to standard LMB chemotherapy (CT) regimen. JClin Oncol. 2016;34:10507-10507.

15. Kantarjian HM, Vandendries E, Advani AS. Inotuzumab ozogamicin for acute lymphoblastic leukemia. N Engl J Med. 2016;375:2100-1.

16. Kantarjian HM, et al. Inotuzumab ozogamicin versus standard therapy for acute lymphoblastic leukemia. N Engl J Med. 2016;375:740-53.

17. Kantarjian H, et al. Inotuzumab ozogamicin, an anti-CD22calecheamicin conjugate, for refractory and relapsed acute lymphocytic leukaemia: a phase 2 study. Lancet Oncol. 2012;13:403-11.

18. Younes A, et al. Results of a pivotal phase II study of brentuximab vedotin for patients with relapsed or refractory Hodgkin's lymphoma. JClin Oncol. 2012;30:2183-9.

19. Majzner RG, Heitzeneder S, Mackall CL. Harnessing the immunotherapy revolution for the treatment of childhood cancers. Cancer Cell. 2017;31:476-85.

20. von Stackelberg A, et al. Phase I/phase II study of blinatumomab in pediatric patients with relapsed/refractoryacute lymphoblasticleukemia. JClin Oncol. 2016;34:4381-9.

21. Kantarjian H, et al. Blinatumomab versus chemotherapy for advanced acute lymphoblastic leukemia. N Engl J Med. 2017;376:836-47.

22. Merli P, Algeri M, Del Bufalo F, Locatelli F. Hematopoietic stem cell transplantation in pediatric acute lymphoblastic leukemia. Curr Hematol Malig Rep. 2019;14:94-105.

23. Bernasconi P, Borsani O. Immune escape after Hematopoietic stem cell transplantation (HSCT): from mechanisms to novel therapies. Cancers (Basel). 2019;12(1):69. https:// doi.org/10.3390/cancers12010069.

24. Lim WA, June $\mathrm{CH}$. The principles of engineering immune cells to treat cancer. Cell. 2017;168:724-40.

25. Labanieh L, Majzner RG, Mackall CL. Programming CAR-T cells to kill cancer. Nat Biomed Eng. 2018;2:377-91.

26. Brentjens RJ, et al. Safety and persistence of adoptively transferred autologous CD19-targeted T cells in patients with relapsed or chemotherapy refractory B-cell leukemias. Blood. 2011;118:4817-28.

27. Porter DL, Levine BL, Kalos M, Bagg A, June CH. Chimeric antigen receptor-modified $\mathrm{T}$ cells in chronic lymphoid leukemia. NEngl J Med. 2011;365:725-33.

28. Maude SL, et al. Chimeric antigen receptor $\mathrm{T}$ cells for sustained remissions in leukemia. $\mathrm{N}$ Engl J Med. 2014;371:1507-17.

29. Lee DW, et al. T cells expressing CD19 chimeric antigen receptors for acute lymphoblastic leukaemia in children and young adults: a phase 1 dose-escalation trial. Lancet. 2015;385:517-28.

30. Wayne AS, et al. Phase 1 study of the anti-CD22 immunotoxin moxetumomab pasudotox for childhood acute lymphoblasticleukemia. Blood. 2017;130:1620-7. 
31. Haso W, et al. Anti-CD22-chimeric antigen receptors targeting B-cell precursor acute lymphoblastic leukemia. Blood. 2013;121:1165-74.

32. Di Stasi A, et al. T lymphocytes coexpressing CCR4 and a chimeric antigen receptor targeting CD30 have improved homing and antitumor activity in a Hodgkin tumor model. Blood. 2009;113:6392-402.

33. Ruella M, et al. Dual CD19 and CD123 targeting prevents antigen-loss relapses after CD19-directed immunotherapies. JClin Invest. 2016;126:3814-26.

34. Qin H, etal. Eradication of B-ALL using chimeric antigen receptor-expressing T cells targeting the TSLPR oncoprotein. Blood. 2015;126:629-39.

35. Kiessling R, Klein E, Pross H, Wigzell H. 'Natural' killer cells in the mouse. II. Cytotoxic cells with specificity for mouse Moloney leukemia cells. Characteristics of the killer cell. Eur J Immunol. 1975;5:117-21.

36. Miller JS, et al. Successful adoptive transfer and in vivo expansion of human haploidentical NK cells in patients with cancer. Blood. 2005;105:3051-7.

37. Rubnitz JE, et al. NKAML: a pilot study to determine the safety and feasibility of haploidentical natural killer cell transplantation in childhood acute myeloid leukemia. JClin Oncol. 2010;28:955-9.

38. Sharma P, Allison JP. Dissecting the mechanisms of immune checkpoint therapy. Nat Rev Immunol. 2020;20:75-6.

39. Callahan MK, Postow MA, Wolchok JD. CTLA-4 and PD-1 pathwayblockade: combinations in the clinic. Front Oncol. 2014;4:385.

40. Alegre M-L, Frauwirth KA, Thompson CB. T-cell regulation by CD28 and CTLA-4. Nat Rev Immunol. 2001;1:220-8.
41. Merchant MS, et al. Phase I clinical trial of Ipilimumab in pediatric patients with advanced solid tumors. Clin Cancer Res. 2016;22:1364-70.

42. Davis KL, Agarwal AM, Verma AR. Checkpoint inhibition in pediatric hematologic malignancies. Pediatr Hematol Oncol. 2017;34:379-94.

43. Chen R, et al. Phase II study of the efficacy and safety of pembrolizumab for relapsed/refractory classic Hodgkin lymphoma. JClin Oncol. 2017;35:2125-32.

44. ICGC PedBrain-Seq Project, et al. The landscape of genomic alterations across childhood cancers. Nature. 2018;555:321-7.

45. Shlien A, etal. Combined hereditary and somatic mutations of replication error repairgenes resultin rapid onset ofultrahypermutated cancers. Nat Genet. 2015;47:257-62.

46. Wedekind MF, Denton NL, Chen C-Y, Cripe TP. Pediatric cancer immunotherapy: opportunities and challenges. Paediatr Drugs. 2018;20:395-408.

Publisher's Note Springer Nature remains neutral with regard to jurisdictional claims in published maps and institutional affiliations.

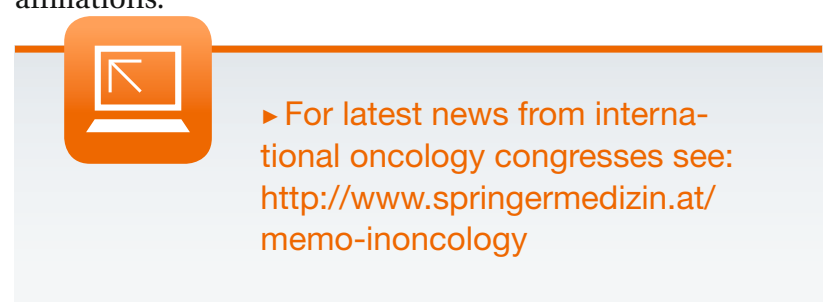

